\title{
Análise fitossociológica de um trecho de floresta ombrófila densa na Amazônia Oriental
}

\section{Phytosociological analysis of a dense ombrophilian forest floor in the Eastern Amazon}

\author{
Robson Carmo Lima ${ }^{1 *}$, Breno Marques da Silva e Silva ${ }^{2}$, Eleneide Doff Sotta ${ }^{3}$, Pierre \\ Couteron 4, Perseu da Silva Aparício 5 , Valdenira Ferreira dos Santos 6 , Renata Lima \\ Bueno 7, Yan Klaus Santos dos Santos 8 , Mikael Bruno Brito Ramos 9
}

${ }^{1}$ Engenheiro Florestal, Mestre em Ciências Florestais pela Universidade Federal Rural de Pernambuco, Doutorando em Biodiversidade e Biotecnologia pela Rede Bionorte pela Universidade Federal do Estado do Amapá. Brasil. E-mail: robsoncl91@hotmail.com * Autor para correspondência

2Biólogo, Doutor em Agronomia pela UNESP, Docente da Universidade do Estado do Amapá-UEAP. Brasil. E-mail: silvabms@hotmail.com ${ }^{3}$ Engenheira Florestal, Doutorado em Forestry and Forest Ecology pelo Universitat Goettingen, Pesquisadora cedida do Ministério da Agricultura, Pecuária e Abastecimento, Brasil. E-mail: esotta@gmail.com

4Engenheiro Florestal, Doutor em Ecologie Végétale Tropicale, Institute of Research for Development-IRD. França. E-mail: pierre.couteron@ird.fr

${ }^{5}$ Engenheiro Florestal, Doutor em Biodiversidade Tropical pela Universidade Federal do Amapá, Docente da Universidade do Estado do AmapáUEAP. Brasil.E-mail: perseu_aparicio@yahoo.com.br

${ }^{6}$ Geóloga, Doutora em Geologia e Geofísica Marinha pela Universidade Federal Fluminense-UFF, Pesquisadora do Instituto de Pesquisas Científicas e Tecnológicas do Estado do Amapá-IEPA. Brasil. E-mail: valdeniraferreira@gmail.com

${ }^{7}$ Engenheira Florestal pelo Instituto Macapaense de Ensino Superior-IMMES. Brasil.E-mail: renatabueno.engf@gmail.com

${ }^{8}$ Engenheiro Florestal pelo Instituto Macapaense de Ensino Superior-IMMES. Brasil. E-mail: yanklaus.ss@gmail.com

${ }^{9}$ Acadêmico de Engenharia Florestal do Instituto Macapaense de Ensino Superior-IMMES Brasil. E-mail: mkl.brito12@gmail.com

\section{Palavras-chave \\ Tipos florestais \\ Fitossociologia \\ Estrutura florestal}

A fitossociologia permite descrever a estrutura do povoamento florestal e favorece as correlações entre as diferentes estruturas das populações de espécies vegetais. A pesquisa teve por finalidade realizar a análise fitossociológica de um trecho de floresta ombrófila densa na Amazônia Oriental. Foram alocadas 4 parcelas de $100 \mathrm{~m} \times 100 \mathrm{~m}$ (um hectare) dentro de um transecto de $2 \mathrm{~km}$ de comprimento por $0,3 \mathrm{~km}$ de largura, onde cada parcela foi subdividida em 100 subparcelas de $10 \mathrm{~m} \times 10 \mathrm{~m}\left(100 \mathrm{~m}^{2}\right)$. O nível de inclusão adotado, foi de DAP $\geq$ $20 \mathrm{~cm}$, sendo que todos os indivíduos com o DAP mínimo foram inventariados e realizado posteriormente o cálculo de seus parâmetros fitossociológicos. Foram inventariados 825 indivíduos, distribuídos em 33 famílias, 69 gêneros e 89 espécies. Os índices de diversidade $\left(H^{\prime}=3,57\right)$ e equabilidade $(J=0,79)$, mostraram que a floresta estudada possui uma boa diversidade. As famílias Fabaceae e Lecythidaceae, obtiveram maior abundância na comunidade estudada, constituindo as principais famílias encontradas em florestas tropicais na Amazônia. As espécies que apresentaram maior Valor de Importância foram: Pouteria guianenses Aubl., Eschweilera coriaceae (DC.) S.A. Mori, Inga paraenses Ducke, Licania paraenses Prance, Dinizia excelsa Ducke, Minquartia guianenses Aubl., Qualea albiflora Warm., Virola michelii Heckel, Alexa grandiflora Ducke e Vouacapoua americana Aubl. Representando $52,13 \%$ dos valores totais de VI. A floresta estudada pode ser considerada bem estruturada, diversa e uniforme, sendo assim, é uma floresta em excelente estado de conservação. As famílias Fabaceae, Sapotaceae, Lecythidaceae, Lauraceae e Vochysiaceae foram as mais importantes do povoamento estudado.

\section{Keywords}

Forest types Phytosociology Forest structure
Phytosociology describes the structure of forest stands and favors the correlations between the different structures of plant species populations. The research aimed to perform the phytosociological analysis of a section of dense ombrophilous forest in the Eastern Amazon. Four plots of $100 \mathrm{~m} \times 100 \mathrm{~m}$ (one hectare) were allocated within a $2 \mathrm{~km}$ long by $0.3 \mathrm{~km}$ wide transect, where each plot was subdivided into $10010 \mathrm{~m} \times 10 \mathrm{~m}$ $\left(100 \mathrm{~m}^{2}\right)$ subplots. The inclusion level adopted was $D B H \geq 20 \mathrm{~cm}$, and all individuals with the minimum $D B H$ were inventoried and their phytosociological parameters were subsequently calculated. 825 individuals were inventoried, distributed in 33 families, 69 genera and 89 species. The diversity index $\left(H^{\prime}=3.57\right)$ and equability index $(J=0.79)$ showed that the studied forest has a good diversity. The Fabaceae and Lecythidaceae families obtained greater abundance in the studied community, constituting the main families found in tropical forests in the Amazon. The species with the highest value of importance were: Pouteria guianensis Aubl., Eschweilera coriaceae (DC.) SA Mori, Inga paraenses Ducke, Licania paraenses Prance, Dinizia excelsa Ducke, Minquartia guianensis Aubl., Qualea albiflora Warm., Virola michelii Heckel, Heckelii Alexa grandiflora Ducke and Vouacapoua American Aubl. Representing 52.13\% of the total VI values. The studied forest can be considered well structured, diverse and uniform, thus, it is a forest in excellent condition. The Fabaceae, Sapotaceae, 


\section{INTRODUÇÃO}

O Brasil é detentor da maior porção da floresta amazônica, que por sua vez é uma das principais repositoras da biodiversidade do mundo. Por isso ampliar o conhecimento sobre as espécies que formam essa floresta é de extrema importância, para que possa haver melhora nas informações que relacionam espécies e fatores ambientais. (SILVA et al., 2014).

O estudo dessas florestas torna-se complicado devido a sua grande extensão, a falta de apoio às pesquisas e o desmatamento em grande escala vêm contribuindo para o desaparecimento de espécies (LIMA et al., 2012). Para um maior entendimento destes povoamentos é necessário um acúmulo sistemático de observações e mensuração da vegetação ao longo do tempo, fortalecendo o conhecimento formado (FREITAS; MAGALHÃES, 2012).

A Fitossociologia é uma ferramenta com inúmeras interfaces na Engenharia Florestal, especialmente com manejo, silvicultura e recuperação de áreas degradadas, sendo primordial seu uso nos estudos de pesquisas (CHAVES et al., 2013). As análises fitossociológicas buscam informações que tornem possível o reconhecimento, diferenciação e definição de população vegetais no que se refere à origem, estrutura, classificação, dinâmica e relações com o meio (OLIVEIRA, 2011; CHAVES et al., 2013).

Os inventários florestais realizados dentro das pesquisas são necessários, pois eles possibilitam conhecimentos e dados das composições florísticas e da estrutura florestal, como: o grau de importância das espécies presentes, verificar quais famílias possuem maior representatividade, demonstrar a diversidade das espécies, isso poderia dizer o quanto uma determinada espécie é importante na área estudada, além de demonstrar se existem espécies raras na região (CHAVES et al., 2013; SANTOS et al., 2016).

A ampla diferença entre distribuição espacial apresentada por diversos ambientes tem fatores vitais que contribuem para esse resultado, os quais estão cada vez mais chamando atenção de pesquisadores para este debate. O principal ponto de se conhecer a estrutura vegetal de uma determinada floresta está constantemente ligado na importância de propor novas metodologias e aplicações de técnicas de manejo e conservação visando a importância daquela determinada área de floresta (PERONI; HERNÁNDEZ, 2011).

A grande variação dos relevos dentro das áreas de florestas, como a distância dela para os rios, igarapés, constrói um montante de situações ambientais a serem levadas em consideração, com diferentes tipos de umidades da base para o topo, transporte de minerais e elementos nutricionais, dossel irregular por conta da topografia do solo e distribuição de luz no interior das florestas, sendo que algumas espécies podem ou não receber uma quantidade de luz diferente (BATISTA et al., 2013).

A presente pesquisa sobre análise fitossociológica de um trecho de floresta ombrófila densa localizado na Amazônia Oriental, faz parte de um projeto maior denominado: Integração de dados multiescala espacial para mapeamento dos tipos florestais e da biomassa no Amapá e na Guiana Francesa (BIOMAP), o qual é desenvolvido em parceria com o Institut de recherche pour le développement (CIRAD), Empresa Brasileira de Pesquisa Agropecuária - EMBRAPA, Universidade do Estado do Amapá - UEAP e a Fundação de Amparo à Pesquisa do Amapá - FAPEAP.

Portanto, este trabalho teve como objetivo descrever a estrutura do povoamento florestal, por meio da análise dos parâmetros fitossociológicos relacionados a estrutura vertical e horizontal. Este estudo vem contribuir com a ampliação do conhecimento científico sobre as florestas nativas presentes na região amazônica, principalmente na Amazônia oriental.

\section{MATERIAL E MÉTODOS}

\section{Caracterização da Área de estudo}

O estudo foi realizado em um trecho de Floresta Ombrófila Densa que está localizado na Amazônia oriental dentro da Reserva de Desenvolvimento Sustentável do Rio Iratapurú RDSI, que por sua vez abrange três municípios do Estado do Amapá, são eles: Laranjal do Jarí, Mazagão e Pedra Branca do Amaparí (Figura 1).

O clima da região onde está localizada a área de estudo é do tipo Am, tropical quente-úmido, caracterizado por temperaturas entre $28^{\circ} \mathrm{C}$ e $30^{\circ} \mathrm{C}$ e pluviosidade anual média de $2.400 \mathrm{~mm}$. O período de chuvas é de dezembro a julho, com médias mensais de $300-400 \mathrm{~mm}$, mas que podem chegar a $500 \mathrm{~mm}$, e o de estiagem é de agosto a novembro, com precipitações médias mensais entre $10 \mathrm{~mm}$ e $180 \mathrm{~mm}$ (GEA, 1999; BARBOSA, 2001). Apresenta-se com um a dois meses secos na maior parte do território. As maiores temperaturas são registradas em outubro e as menores nos meses de 
fevereiro e abril (AMAPÁ, 2015).

A vegetação é caracterizada como mata de Floresta Ombrófila Densa e tem por sua vez características significativas, como exemplo, sua vegetação é constituída por matas conhecidas como perenifólia (MENEZES et al., 2010). Algumas das principais características da Floresta Ombrófila Densa que mais se destacam são: alta diversidade por unidade de área, muita competição de espécies por luz solar, estratos diferenciados, dominância e endemismo de espécies (IEPA, 2008). Também é marcada por espécies com características emergentes, outras com frequência madeireiras e diâmetros maiores dos troncos. O destaque dessa tipologia é atribuído à ocorrência de algumas espécies com a presença de essências oleaginosas, aromáticas, medicinais, e produtoras de frutos comestíveis (IEPA, 2008).

A região onde está situada a RDSI encontra-se no domínio morfoclimático amazônico (AB'SABER, 1970), cujas suas principais características são um relevo formado especialmente por depressões onde ocorrem os baixos planaltos (platôs) e planícies aluviais. Nas bordas destas depressões estão situadas as maiores altitudes deste domínio, sobretudo nas bordas norte e sul, onde estão os planaltos das Guianas e Central. Os baixos planaltos têm origem sedimentar, sofrem processo de erosão e são as mais abrangentes formas de relevo da Amazônia, já as planícies ocorrem somente ao longo de alguns trechos de rios regionais (AMAPÁ, 2015).

Figura 1. Localização da área de estudo.

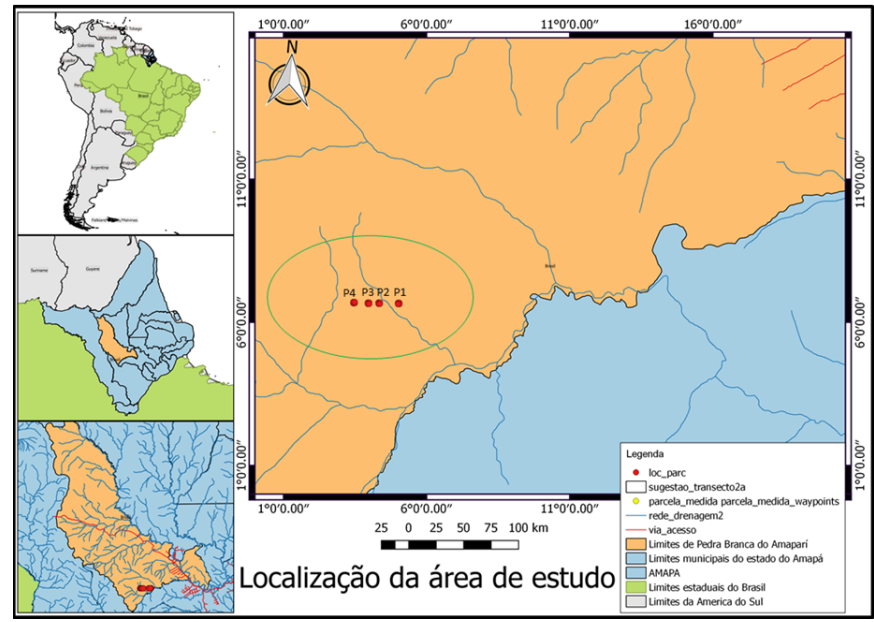

\section{Inventário Florestal}

O método de amostragem usado foi a amostragem sistemática, onde foram alocadas quatro parcelas de 1 ha (100 $\mathrm{m} \times 100 \mathrm{~m}$ ), distanciadas em 0,5 km entre si, dentro de um transecto de $2 \mathrm{~km}$ de comprimento por 0,3 km de largura. Cada parcela foi subdividida em 100 subparcelas de $100 \mathrm{~m}^{2}$
(10 m x $10 \mathrm{~m})$.

Os dados amostrados foram: número de indivíduos (n), DAP, altura total $(H T)$, altura comercial $(H C)$, localização das árvores nas subparcelas por coordenadas $\mathrm{X}, \mathrm{Y}$ e nome vulgar de cada indivíduo. Para a obtenção do DAP, todas as árvores localizadas nas parcelas que continham o DAP mínimo de inclusão (DAP $\geq 20 \mathrm{~cm}$, DAP- Diâmetro à Altura do Peito, medido a 1,3 $\mathrm{m}$ do solo), foram inventariadas.

A HT foi mensurada com o auxílio de um Hipsômetro digital (Tru Pulse 360), onde o mensurador colocava a trena no término da sua altura (cabeça), direcionando o laser para o topo da árvore, somando posteriormente o valor obtido pelo aparelho com a altura do mensurador. Para a $\mathrm{HC}$ a mensuração foi realizada do solo até o primeiro galho da árvore ou até a parte da árvore que continha volume comercializável.

A HC foi definida como a parte do fuste a partir do nível do solo até a primeira bifurcação do tronco, foi mensurada também pela trena digital a laser, direcionando o laser na primeira bifurcação ou defeito do fuste. As localizações das árvores dentro das parcelas foram determinadas por coordenadas geográficas sendo auxiliadas por um aparelho Global Positioning System (GPS).

\section{Análise da Estrutura Florestal}

\section{Estrutura horizontal}

A estrutura horizontal da floresta foi avaliada por meio de parâmetros fitossociológicos descritos por Soares et al. (2011) para o conjunto das quatro parcelas (Figura 2). Posteriormente, foi realizada a mesma avaliação, por parcela. Os parâmetros fitossociológicos calculados foram:

Densidade Absoluta - DA (Equação 1), Densidade Relativa - DR (Equação 2):

$$
D A_{i}=\frac{n_{i}}{A}(1) D R_{i}=\frac{D A_{i}}{\sum_{i=1}^{S} D A_{i}} * 100
$$

Em que: $\mathrm{DAi}$ = densidade absoluta da i-ésima espécie em número de indivíduos/ha; ni = número de indivíduos da iésima espécie na amostragem; $A=$ área total amostrada em ha; $\mathrm{DRi}=$ densidade relativa da i-ésima espécie em porcentagem; e $\mathrm{s}=$ número de espécies amostradas.

Dominância Absoluta - DoA (Equação 3) e Dominância relativa - DoR (Equação 4):

$$
D o A_{i}=\frac{A B_{i}}{A}(3) D o R_{i}=\frac{A B_{i}}{\sum_{i=1}^{S} A B_{i}} * 100(4)
$$

Em que: DoAi= dominância absoluta da i-ésima espécie 
em $\mathrm{m} 2 / \mathrm{ha} ; \mathrm{ABi}=$ área basal (somatório das áreas seccionadas) da i-ésima espécie na amostragem em $m 2$, na área amostrada; $A=$ área amostrada em ha; DoRi= dominância relativa da i-ésima espécie em porcentagem; e s = número de espécies amostradas.

Frequência Absoluta - FA (Equação 5), Frequência relativa - FR (Equação 6):

$$
\begin{gathered}
F A_{i}=\frac{U_{i}}{U_{t}} * 100(5) \\
F R_{i}=\frac{F A_{i}}{\sum_{i=1}^{S} F A_{i}} * 100(6)
\end{gathered}
$$

Em que: $F A i$ = frequência absoluta da i-ésima espécie; Ui= número de unidades de amostra em que se encontrou i-ésima espécie; Ut= número total de unidades medidas; Área basal (somatório das áreas seccionadas) da i-ésima espécie na amostragem em $\mathrm{m} 2$, na área amostrada; $A=$ área amostrada em ha; $\mathrm{FRi}=$ frequência relativa da i-ésima espécie em porcentagem.

\section{Valor de importância (VI)}

O valor de importância é resultante da média aritmética da densidade relativa da i-ésima espécie em porcentagem; dominância relativa da i-ésima espécie em porcentagem e frequência relativa da i-ésima espécie em porcentagem (Equação 7):

$$
I V I_{i}(\%)=\frac{D R_{i}+D o R_{i}+F R_{i}}{3}(7)
$$

\section{Índice de Similaridade (ISJ)}

Para avaliar a similaridade florística entre as parcelas foi utilizado o índice de similaridade de Jaccard (Equação 8):

$$
I S J=\frac{c}{a+b-c} * 100(8)
$$

Em que: $a=$ número espécies da comunidade $A ; b=$ número espécies da comunidade $B ; C=$ número espécies em comum.

Índice de diversidade $\left(H^{\prime}\right)$

Para avaliar a diversidade florística entre as parcelas foi utilizado o índice de diversidade de Shannon (Equação 9):

$$
H^{\prime}=\sum_{e=1}^{S} \frac{n_{i}}{N} * \ln * \frac{n_{i}}{N}(9)
$$

Em que: $s$ = número de espécies amostradas; ln= logarítmo neperiano; $\mathrm{N}=$ número de indivíduos da i-ésima espécie na amostragem.
Índice de equabilidade de Pielou (J)

Para avaliar a uniformidade da distribuição dos indivíduos entre as espécies existentes, utiliza-se a seguinte forma (Equação 10), que varia de 0 a 1 , o qual mais próximo de 1 , mais uniforme a distribuição dos indivíduos nas espécies.

\section{$\mathbf{J}=\mathbf{H}^{\prime} / \mathbf{H}^{\prime} \max (10)$}

Em que: $H^{\prime}=$ índice de diversidade de Shannon da comunidade; $H^{\prime} \max =\ln (S) ; S=$ número total de espécies amostradas.

\section{Coeficiente de Mistura de Jentsch}

O coeficiente ou quociente de mistura (QM) é um fator que mede a intensidade de mistura das espécies, ele indica em média o número de indivíduos dentro de cada espécie amostrada na comunidade (LAMPRECHT, 1964 apud SOUZA; SOARES, 2013). Calculado pela expressão (Equação 11):

\section{QM: S/N (11)}

Em que: S: número total de espécies amostradas; $\mathrm{N}$ : número total de indivíduos amostrados.

O número de classes de diâmetro e de altura foram estimados pela fórmula de Sturges, adaptada por Higuchi, Santos e Lima (2008) (Equação 12):

$$
\mathbf{K}=\mathbf{1}+\mathbf{3 , 3 3} * \log (\mathbf{n})(12)
$$

Em que: $\mathrm{k}$ = número de classes; $\mathrm{n}=$ número de indivíduos amostrados.

Posteriormente, os diâmetros e alturas foram divididos em classes e elaborados gráficos de distribuição.

\section{Estrutura vertical}

Inicialmente foi realizada uma análise descritiva dos diâmetros e das alturas das árvores. Essa análise baseia-se na interpretação das medidas descritivas de tendência central como a média aritmética, medidas de dispersão, como variância, desvio padrão, erro padrão da média (E.P.M.) e coeficiente de variação (CV\%).

A estrutura vertical foi analisada considerando a posição sociológica de cada árvore. Para isso foram definidos três estratos, os critérios de estratificação de SOUZA (1998) e utilizado por MARISCAL-FLORES (1993), que estratifica a floresta em três estratos de altura total:

Estrato Inferior - árvores com altura total $(\mathrm{H})$ menor que a altura média $(\mathrm{Hm})$ menos uma unidade de desvio padrão $(1 \sigma)$ das alturas totais, ou seja, $\mathrm{H}<(\mathrm{Hm}-1 \sigma)$; Estrato Médio compreende as árvores com $(\mathrm{Hm}-1 \sigma) \leq \mathrm{H}<(\mathrm{Hm}+1 \sigma)$;

Estrato Superior - compreende as árvores com $\mathrm{H} \geq(\mathrm{Hm}+$ 
$1 \sigma)$.

O estudo da estrutura vertical nas florestas de terra firme mostra uma ideia da importância das espécies, considerando a sua participação nos estratos verticais que o povoamento apresenta. Os estratos verticais que são encontrados na floresta podem ser classificados em: espécies dominantes, intermediárias e dominadas.

Aquelas espécies que possuem um maior número de indivíduos representantes em cada um desses estratos, certamente apresentam uma maior importância ecológica no povoamento em estudo.

A presença de indivíduos de uma mesma espécie em todos os estratos é um índice positivo quanto à contribuição da espécie para o desenvolvimento da vegetação. Os estratos foram analisados de forma a obter um Valor Fitossociológico (Equação 13) por estrato, expresso em porcentagem:

\section{$\mathrm{VF}=\frac{\text { Número de individuos no estrato }}{\text { Número total de indivíduos no estrato }} .100$ (13)}

A posição sociológica absoluta foi calculada da seguinte forma (Equação 14):

\section{PsA $=[\mathbf{V F}(\mathbf{E i}) \cdot \mathbf{n}(\mathbf{E i})]+[\mathbf{V F}(\mathbf{E m}) \cdot \mathbf{n}(\mathbf{E m})]+[\mathbf{V F}(\mathrm{Es}) \cdot \mathbf{n}(\mathrm{ES})]$ (14)}

Em que: PsA = Posição Sociológica Absoluta; $\mathrm{VF}=$ Valor

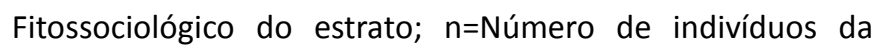
espécie considerada.

A posição sociológica relativa foi calculada da seguinte forma (Equação 15):

$$
P s R=\frac{P s A}{\sum P s A} .100(15)
$$

\section{Análise dos Dados}

Os dados coletados, foram digitalizados em planilhas do Word 2013 e planilhas do Excel. Os dados das parcelas foram submetidos a análise estatística por meio do pacote $\mathrm{R}$ com interface Studio.

\section{RESULTADOS E DISCUSSÃO}

\section{Analise florística}

Nos quatro hectares amostrados foram mensurados 825 indivíduos, distribuídos em 89 espécies, 69 gêneros e 33 famílias. O resultado para o total de árvores inventariadas está dentro dos valores encontrados em florestas tropicais na Amazônia (PINHEIRO et al., 2007; SILVA et al., 2008; OLIVEIRA, 2016). Santos (2017) estudando uma área de 5 ha de floresta no município de Porto Grande - AP, encontrou 1.041 indivíduos, sendo que seu nível de inclusão foi o mesmo utilizado na atual pesquisa (DAP $\geq 20 \mathrm{~cm}$ ). Este valor, está em conformidade com os resultados encontrados no presente estudo, sendo que a média de indivíduos por hectare de Santos (2017), foi de 208,2 ind./ha e o da presente pesquisa, a média foi de 206,25 ind./ha.

$\mathrm{O}$ índice de diversidade de Shannon $\left(\mathrm{H}^{\prime}\right)$ calculado foi de 3,57 nats/ind., comparando este valor com outros estudos realizados na Amazônia (CARIM et al., 2013; CONDÉ; TONINI 2013; OLIVEIRA, 2016; ANDRADE et al., 2017), observa-se que a floresta em estudo, está dentro dos valores encontrados para a região. Resultados acima de 3,11 nats/ind., indicam formações vegetais bem conservadas (SAPORETTI JUNIOR et al., 2003 apud FERREIRA JUNIOR et al., 2008).

Alguns fatores podem influenciar nos resultados calculados para diversidade (MELO, 2008; OLIVEIRA et al., 2015), como o nível de inclusão adotado para cada pesquisa. A maioria dos estudos, utilizam nível de inclusão mínimo entre 5 e 10cm (LIMA et al., 2012; CARIM et al., 2013; CONDÉ; TONINI, 2013). Silva et al (2008) estudando uma área de terra firme em Manaus-AM, com nível de inclusão (DAP $\geq 20 \mathrm{~cm}$ ), obteve índice de diversidade de Shannon igual a 2,71 nats/ind. Levando em consideração o DAP mínimo, pode-se dizer que a floresta do atual estudo, possui elevada diversidade local.

$\mathrm{O}$ índice de equabilidade de Pielou (J) encontrado neste estudo foi de 0,79 , este valor, mostra que a floresta possui uma boa uniformidade na distribuição dos indivíduos por espécie. Condé e Tonini (2013), encontraram o valor de 0,64 para a equabilidade estudando uma floresta ombrófila densa no município de Caracaraí-RR, este valor é considerado baixo para a Amazônia. De acordo com alguns estudos (ALMEIDA et al., 2012; ANDRADE et al., 2015; BATISTA et al., 2015), os níveis de uniformidade considerados bom, variam entre 0,75 e 0,92 .

De acordo com Finol (1975), o quociente de mistura (QM) das florestas tropicais, apresentam nove indivíduos por espécies, aproximadamente (ALMEIDA et al., 2012). O quociente de mistura deste estudo ( $Q M=1: 9)$, mostra que cada espécie está representada em média por nove indivíduos, o qual está de acordo com o esperado para as florestas tropicais, colaborando com os resultados encontrados para diversidade e equabilidade.

As espécies que apresentaram o maior número de indivíduos, foram Pouteria guianensis (136), Eschweilera coriaceae (78), Inga paraensis (45), Licania paraensis (38) e Virola michelii (33), que representam $40 \%$ do total de indivíduos amostrados (Figura 3). Das espécies inventariadas, 29 ocorreram com apenas um indivíduo cada, representando $32,6 \%$ do total de espécies (Figura 2). 
Figura 2. Número de indivíduos por espécie para as quatro parcelas da área de estudo.

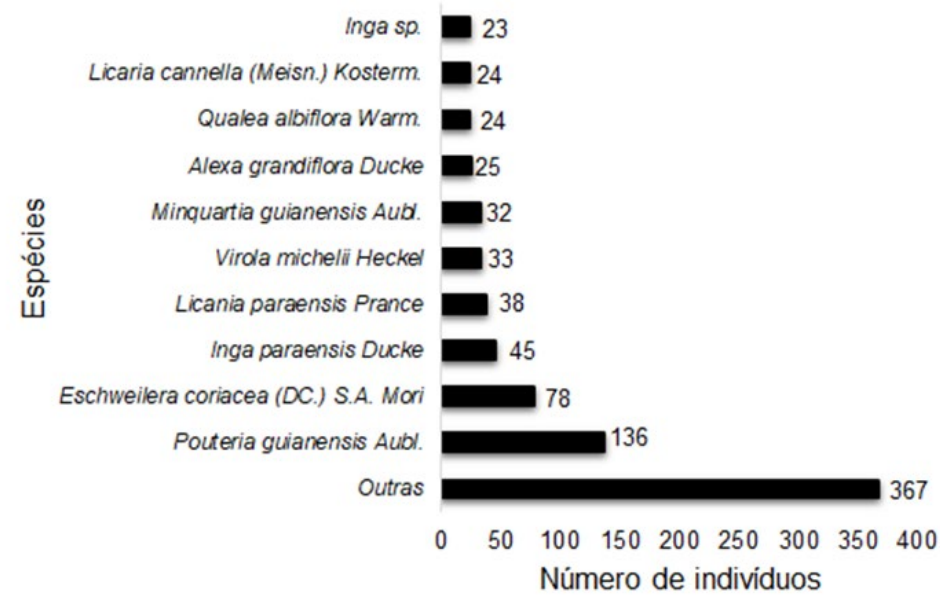

Dionísio et al. (2016) registrou 33\% de espécies raras, as quais ocorrem com apenas um indivíduo na área de estudo. De acordo com o mesmo autor, os estudos na Amazônia registram valores entre $30 \%$ e $55 \%$ de espécies localmente raras (SILVA et al., 2010; KUNZ et al., 2014 apud DIONISIO et al., 2016), isso se deve ao alto índice de diversidade e a dominância de algumas espécies na floresta, as quais tendem a agrupar maior número de indivíduos no espaço (CARIM et al., 2013), sendo necessário uma área maior para a representação destes indivíduos.

Com relação às famílias destacaram-se com elevada riqueza a Fabaceae (20 espécies); Lauraceae (7 espécies) e Apocynaceae, Lecythidaceae e Sapotaceae (6 espécies cada); totalizando $49,44 \%$ da riqueza. Mais da metade das famílias $(53,1 \%)$ contribuíram com apenas uma espécie. As famílias de maior abundância foram a Fabaceae (205 indivíduos), Sapotaceae (150 indivíduos); Lecythidaceae (120 indivíduos); Lauraceae (43 indivíduos) e Chrysobalanaceae (42 indivíduos), totalizando $67,88 \%$ dos indivíduos amostrados (Figura 3).

Pereira et al. (2011) encontrou em uma área na RDSI, as famílias Fabaceae Lauraceae, Sapotaceae e Lecythidaceae com maior riqueza específica, corroborando com o estudo presente. E algumas das famílias que obtiveram maior abundância em seu estudo, também foram Fabaceae, Lecythidaceae, Lauraceae, Sapotaceae. Outros estudos em florestas da Amazônia mostram que essas famílias são as mais representativas, tanto em riqueza, como em abundância (GUIMARÃES; CARIM, 2008; PEREIRA et al., 2011; CARIM et al., 2013; CONDÉ; TONINI; 2013; BATISTA et al., 2015).

Os gêneros de maior representatividade foram Pouteria, com 144 indivíduos, Eschweilera com 102; Inga, com 71 indivíduos; Licania com 42 e Virola, com 40 indivíduos representados. Estes gêneros, também foram citados por Lima et al. (2012) em estudo feito em uma floresta de terra firme contribuindo efetivamente para a sua formação. Esses e outros estudos mostram o valor e a importância dessas espécies para o desenvolvimento das florestas na Amazônia (SOUSA et al., 2018).

Figura 3. Número de indivíduos por família para as quatro parcelas da área de estudo.

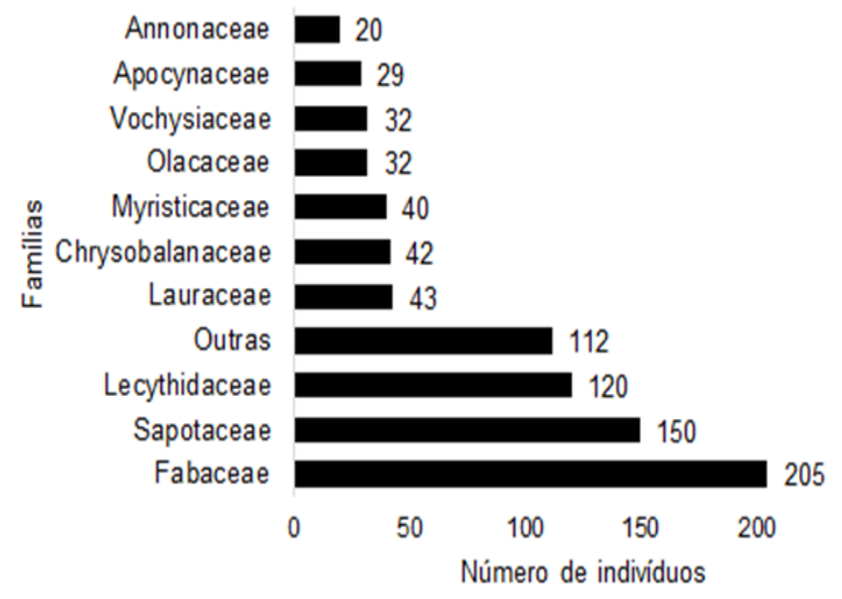

O índice de similaridade de Jaccard, possui semelhança entre as parcelas com valores iguais ou acima de 0,5, resultados com valores próximos ou igual a um, referem-se a alta similaridade entre parcelas (FERREIRA JUNIOR et al., 2008). O valor médio calculado para similaridade, usando presença e ausência de espécies, foi igual a 0.4138 , indicando que existe baixa similaridade ente as áreas estudadas. 0 menor valor obtido para este índice ocorreu na comparação entre as parcelas P1 e P3, que foi de 0.2881 correspondendo à alta dissimilaridade entre os povoamentos.

Esses valores mostram que a floresta possui uma alta diversidade de espécies, sendo que as parcelas mostraram pouca semelhança entre si, fator que leva a considerar que a floresta em estudo possui diferentes fitofisionomias. Uma explicação para este resultado, seria a diferença de altura presente entre as parcelas. Segundo Andrade et al. (2017), estudos demonstram que florestas de terra firme, possuem alta diversidade nos ambientes, com poucos indivíduos por espécie e baixa similaridade florística entre parcelas contíguas.

O dendrograma abaixo (Figura 4), mostra que apenas as parcelas P2 e P4 possuem semelhança entre si, com a formação de três grupos. Este fator pode estar relacionado com a localização das parcelas em diferentes níveis de altura. O grupo 1 , mostrou-se o mais distinto relacionado ao restante, isto se deve ao fato de que a parcela P1 encontra-se próximo ao curso d'água e com bastante presença de palmeiras na área. 
Figura 4. Dendrograma descritivo da similaridade entre as parcelas amostradas na área de estudo, tendo como variável as espécies.

\section{Cluster Dendrogram}

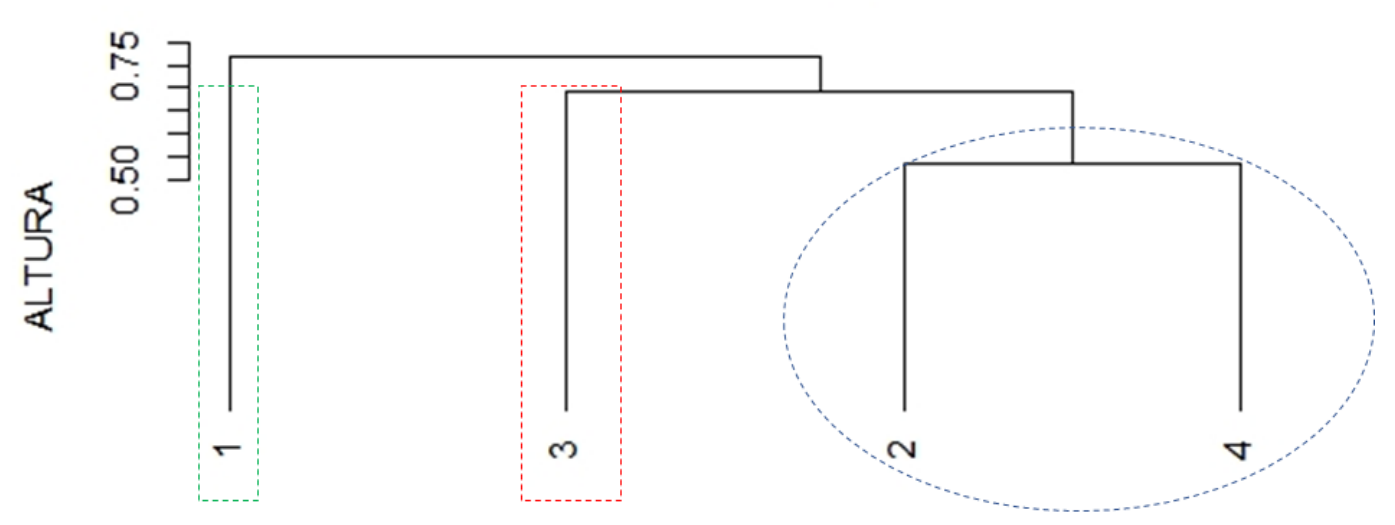

\section{PARCELA \\ hclust (", "complete")}

Também foi observada a ocorrência de similaridade entre as parcelas P2 e P4 e dissimilaridade entre essas e as demais (P1, P3) para a variável altura. A análise continuou identificando a formação de três grupos florestais distintos (Figura 6). Pode-se concluir que o grupo com maior similaridade ( $\mathrm{P} 2$ e $\mathrm{P} 4$ ), além de possuírem espécies semelhantes, também obtêm classe de altura similar dos espécimes presentes nas áreas.

$O$ teste $F$ indicou a ocorrência de diferença altamente significativa ao nível de $1 \%$ de probabilidade $(p=0.0000002)$ para as médias das alturas por parcela. 0 teste de Tukey mostrou que a vegetação mensurada na parcela P3 constitui um grupo que se diferencia dos demais possuindo a maior média de altura (21.06 m). P4 e P2 são iguais e formam um grupo com características semelhantes entre si (Tabela 1).
Esses resultados para a variável altura ratificam o observado pela análise de similaridade citada acima. Não ocorreu diferença significativa entre as parcelas para a variável DAP.

\section{Análise Fitossociológica}

As espécies que apresentaram maior Valor de Importância (VI) foram: Pouteria guianensis Aubl. $(37,7)$, Eschweilera coriaceae (DC.) S.A. Mori (24,9), Inga paraensis Ducke $(15,5)$, Licania paraensis Prance $(12,6)$, Dinizia excelsa Ducke $(12,4)$, Minquartia guianensis Aubl. (11,6), Qualea albiflora Warm. $(11,1)$, Virola michelii Heckel (11), Alexa grandiflora Ducke $(10,9)$ e Vouacapoua americana Aubl $(8,7)$, representando $52,13 \%$ dos valores totais de VI. A espécie Pouteria guianensis

Tabela 1. Análise descritiva da variável altura DAP mensurada nas parcelas.

\begin{tabular}{ccccc}
\hline \multicolumn{5}{c}{ ALTURA } \\
\hline Parcela & Média & Variância & D. Padrão & C. Variação \\
\hline P1 & $16.34 \mathrm{a}$ & 17.3 & \pm 4.16 & 25.45 \\
P2 & $18.78 \mathrm{~b}$ & 19.56 & \pm 4.42 & 23.55 \\
P3 & $\mathbf{2 1 . 0 6 ~ c}$ & 29.6 & \pm 5.44 & 25.84 \\
P4 & $17.31 \mathrm{ab}$ & 22.89 & \pm 4.78 & 27.64 \\
\hline & & DAP & & 58.77 \\
\hline P1 & $35.63 \mathrm{a}$ & 438.55 & \pm 20.94 & 43.65 \\
P2 & $36.43 \mathrm{a}$ & 252.77 & \pm 15.90 & 69.23 \\
P3 & $36.71 \mathrm{a}$ & 646.01 & \pm 25.42 & 41.81 \\
\hline
\end{tabular}


Aubl. obteve valores significativos nos três parâmetros, seguido de Eschweilera coriaceae (DC.) S.A. Mori que obteve o segundo maior valor para os três parâmetros analisados, ficando atrás somente de Dinizia excelsa Ducke, no quesito dominância.

Pouteria guianensis Aubl. e Eschweilera coriaceae (DC.) S.A. Mori também estiveram entre as principais espécies de VI em uma pesquisa realizada em floresta de terra firme no Estado do Pará, por Oliveira et al. (2016a), as quais obtiveram valor significante para os três parâmetros fitossociológicos. Essas espécies e as demais, também foram encontradas em outros estudos (LIMA et al., 2012; BATISTA et al., 2015; ANDRADE et al., 2017), mostrando a importância delas para o ecossistema local. Todos os resultados para Densidade, Dominância, Frequência e Índice de Valor de Importância são especificados abaixo (Tabela 2).

O índice de valor de importância familiar (IVIF), indicou as famílias Fabaceae, Sapotaceae, Lecythidaceae, Lauraceae e Vochysiaceae, como as mais importantes do estudo, representando $66,67 \%$ do total de indivíduos amostrados. Observando o gráfico (Figura 7), nota-se que a família Fabaceae possui valores significativos nos três parâmetros fitossociológicos, sendo a família mais representativa, portanto, com maior importância familiar no estudo. A família Fabaceae está presente na maior parte dos trabalhos fitossociológicos realizados na Amazônia (CARIM et al., 2013; CONDÉ; TONINI 2013), tomando na maioria das vezes a primeira posição em valor de importância, podendo ser considerada a família de maior valor para as comunidades da floresta Amazônica.

Carim et al. (2013) identificou a família Fabaceae como sendo a espécie com maior riqueza específica, densidade e dominância relativa, seguida de Sapotaceae pelo porte de suas espécies. Valores esses também encontrados por Pereira et al. (2011), onde se mostrou mais uma vez a família
Fabaceae no topo da importância para florestas de terra firme, seguido de Lauraceae e Sapotaceae. Considerando esses resultados pode-se dizer que a família Sapotaceae também é uma das famílias mais importantes para as florestas de terra firme na Amazônia.

As famílias Lecythidaceae, Lauraceae e Vochysiaceae, também aparecem nos estudos realizados na Amazônia (CARIM et al., 2013; CONDÉ; TONINI, 2013; ANDRADE et al., 2017), que confirmam a grande importância dessas famílias para a manutenção das florestas de terra firme da Amazônia. Carim et al. (2013) aponta que a família Lecythidaceae serve como indicador de florestas intactas, ou seja, em ótimo estado de conservação.

Em relação à densidade absoluta foram obtidos os seguintes valores por parcela: 112 ind./ha (parcela 1), 254 ind./ha (parcela 2), 194 ind./ha (parcela 3) e 265 ind./ha (parcela 4). O número de indivíduos foi considerado satisfatório, dado ao nível de inclusão adotado no inventário florestal.

O esforço amostral foi considerado satisfatório, pois o erro amostral observado foi igual a 6,926 \%, menor que os $10 \%$ aplicado para a floresta Amazônica. Um fator que pode ter contribuído também para a não estabilidade total da curva é o nível de inclusão adotado na pesquisa (DAP $\geq 20 \mathrm{~cm}$ ), sendo que o valor de inclusão geralmente usado por outros pesquisadores em estudos na Amazônia é de $10 \mathrm{~cm}$ (LIMA et al., 2012; CARIM et al., 2013; SILVA et al., 2014). Schilling e Batista (2008) concluíram que ao estudar florestas tropicais, a curva não estabiliza mesmo com grandes áreas, por conta de sua elevada riqueza, também mostrado nos estudos de Condé e Tonini (2013).

A distribuição diamétrica da floresta em estudo (Figura 5), mostra a formação de um J invertido, apresentando maior número de indivíduos jovens nas classes de menor diâmetro, e menor número de indivíduos nas classes de maior diâmetro,

Tabela 2. Parâmetros fitossociológicos do trecho florestal inventariado em que IVI = Índice de Valor de Importância;

FA $=$ Frequência Absoluta; DA $=$ Densidade Absoluta; DoA $=$ Dominância Absoluta; FR $=$ Frequência Relativa; DR $=$ Densidade Relativa; DoR = Dominância Relativa.

\begin{tabular}{|c|c|c|c|c|c|c|c|}
\hline ESPÉCIE & FA & DA & Do.A & FR & DR & Do.R & IVI \\
\hline Pouteria guianensis Aubl. & 75 & 136 & 11.1 & 11 & 16.5 & 10.2 & 37.7 \\
\hline Eschweilera coriacea (DC.) S.A. Mori & 53 & 78 & 8.2 & 7.8 & 9.5 & 7.6 & 24.9 \\
\hline Inga paraensis Ducke & 39 & 45 & 4.7 & 5.7 & 5.5 & 4.3 & 15.5 \\
\hline Licania paraensis Prance & 32 & 38 & 3.6 & 4.7 & 4.6 & 3.3 & 12.6 \\
\hline Dinizia excelsa Ducke & 13 & 13 & 9.6 & 1.9 & 1.6 & 8.9 & 12.4 \\
\hline Minquartia guianensis Aubl. & 26 & 32 & 4.3 & 3.8 & 3.9 & 3.9 & 11.6 \\
\hline Qualea albiflora Warm. & 21 & 24 & 5.6 & 3.1 & 2.9 & 5.1 & 11.1 \\
\hline Virola michelii Heckel & 29 & 33 & 3.0 & 4.2 & 4.0 & 2.8 & 11 \\
\hline Alexa grandiflora Ducke & 22 & 25 & 5.1 & 3.2 & 3.0 & 4.7 & 10.9 \\
\hline Vouacapoua americana Aubl. & 15 & 18 & 4.7 & 2.2 & 2.2 & 4.3 & 8.7 \\
\hline
\end{tabular}


este comportamento é encontrado em florestas balanceadas, ou seja, florestas que estão em equilíbrio, logo, a floresta estudada está enquadrada como floresta uma bem preservada.

Resultados similares também foram encontrados por Santos (2017), o qual também utilizou o nível de inclusão $D A P \geq 20 \mathrm{~cm}$. Os números de indivíduos foram satisfatórios considerando o valor de inclusão adotado na pesquisa, se comparado com outros estudos, onde o valor geralmente adotado é de 10cm de DAP (SILVA, 2010; SILVA et al., 2014; SANTOS et al., 2016).

A distribuição diamétrica por parcela também apresentou as características esperadas para as florestas naturais não perturbadas. Porém, foi observado que a parcela P1 possui menor quantidade de indivíduos na primeira classe, quando comparado às demais parcelas. Isso pode ter ocorrido devido ela estar localizada próximo de um curso d'água onde a ocorrência de palmeiras foi maior que nas outras áreas amostradas, o que justifica o número menor de indivíduos encontrados para essa parcela (112 indivíduos). A distribuição diamétrica é bastante semelhante nas parcelas P2 e P4 (Figura 5).

Em relação à altura dos indivíduos amostrados, o valor mínimo da altura foi de $9 \mathrm{~m}$ e máxima foi de $39 \mathrm{~m}$ e a altura geral média foi igual a $18,5 \mathrm{~m}$. A maioria dos indivíduos possui entre 10 e 20 metros de altura. Foi observado que a partir dos $20 \mathrm{~m}$, à medida que a altura aumenta há uma diminuição no número de indivíduos nas classes (Figura 9).

Santos (2017) concentrou a maior parte de seus indivíduos no intervalo de 11 a 27 metros de altura, e altura geral média foi de 18,7 metros, com árvores podendo chegar até 37 metros de altura, esses valores se aproximam dos resultados encontrados na presente pesquisa, corroborando com o fato de que a floresta em estudo está em ótimo estado de conservação, com indivíduos que se encontram em equilíbrio na floresta, tratando-se de uma área florestal intacta.

A distribuição altimétrica dos indivíduos por parcela, mostra que as parcelas P2 e P4 possuem distribuição semelhantes dos indivíduos nas classes de altura, o mesmo não foi observado nas demais parcelas (Figura 10).

A parcela $\mathrm{P} 3$ apresentou um número menor de indivíduos na classe inicial e a parcela $\mathrm{P} 1$, mesmo com um número menor de indivíduos amostrados possui uma distribuição altimétrica entre as classes com um número maior de indivíduos na primeira casse, estando no mesmo aspecto da P4, porém, com níveis diferentes de indivíduos.

A estratificação vertical da floresta (Figura 13), a qual foi dividida em estrato inferior, médio e superior, mostra que o estrato que concentrou o maior número de indivíduos, foi o estrato médio, com um total de 574 árvores e alturas que variam entre 13,5 e 23,5 metros, representando $69,57 \%$ do total de indivíduos. O estrato superior, agrupou 151 indivíduos, correspondendo a $18,3 \%$ do total. Dionísio et al. (2016) registraram 70,29\% dos indivíduos no estrato médio e $16 \%$ no estrato superior, resultados semelhantes foram encontrados também por Condé e Tonini (2013), o qual registraram $71,30 \%$ para o estrato médio e $16,6 \%$ para o estrato superior. Corroborando com os resultados encontrados no presente trabalho.

$O$ intervalo de altura dos estratos arbóreos depende do desenvolvimento da floresta (LUANA, 2017). Segundo Souza et al. (2003), a estrutura vertical se torna um importante indicador de sustentabilidade quando se trata de inventário fitossociológico (LUANA, 2017). As espécies que estão representadas nos três estratos arbóreos, possuem uma boa representatividade na estrutura vertical, mostrando que essas

Figura 5. Distribuição diamétrica para todos os indivíduos inventariados na amostragem.

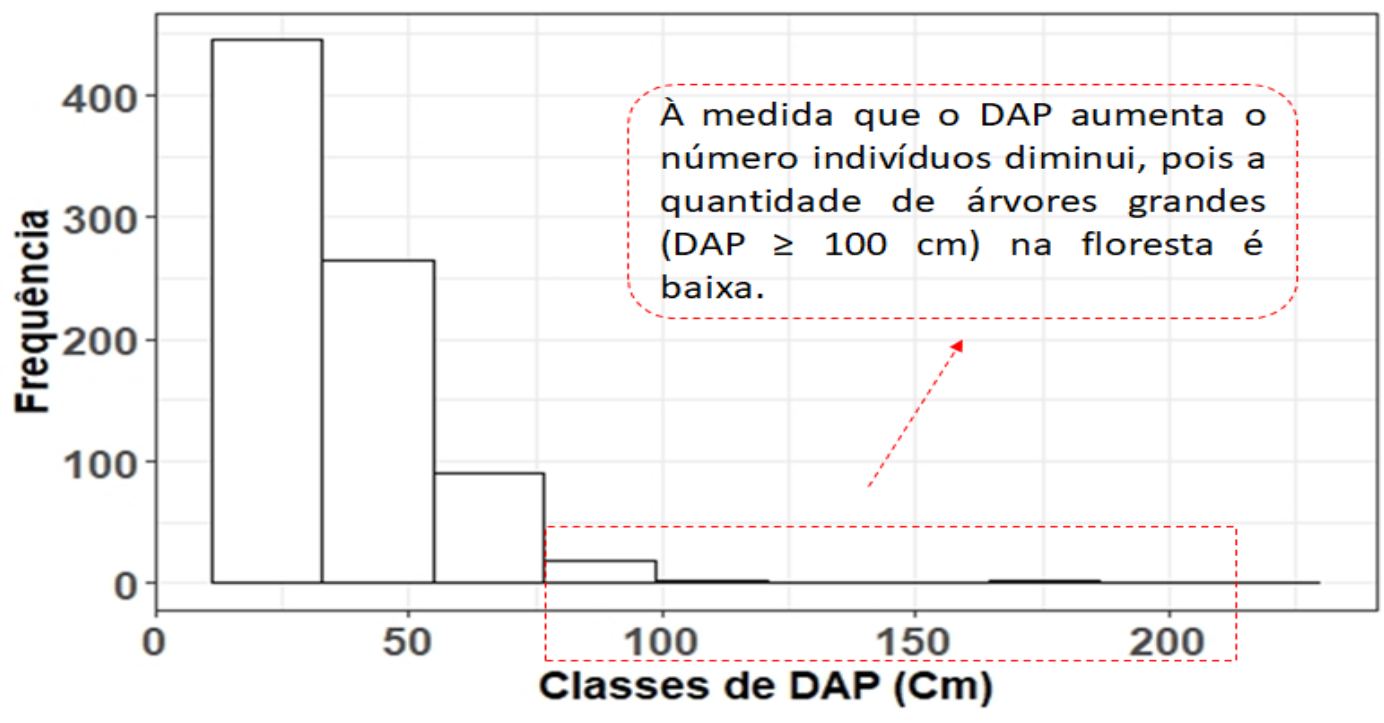


espécies dominam a floresta, pois elas são encontradas em todos os estratos. Na presente pesquisa, foram registradas 23 espécies que participam dos três estratos arbóreos, o que representa $25,84 \%$ da população estudada.

\section{CONSIDERAÇÕES FINAIS}

As famílias Fabaceae, Sapotaceae, Lecythidaceae, Lauraceae e Vochysiaceae foram as mais importantes do povoamento estudado. A ocorrência e importância elevada dessas famílias corresponde ao elevado grau de conservação da floresta analisada. Além disso, é uma floresta altamente diversa.

Os resultados obtidos no estudo, para a estrutura horizontal e vertical, mostraram que a floresta possui uma distribuição regular dos indivíduos. Essa distribuição regular ocorre tanto a nível de espécies como para classes de DAP e os estratos arbóreos.

A floresta estudada possui a formação de pelo menos três tipos florestais identificados através da análise de similaridade entre as espécies e altura do povoamento de cada parcela. Isso pode ser devido aos diferentes níveis de altitude e de solo do local.

Mesmo a curva espécie área não estabilizando, os valores do índice de Shannon e da similaridade de Pielou, foram considerados satisfatórios, pois se enquadram dentro dos padrões para florestas tropicais da Amazônia.

A presente pesquisa registrou valores importantes alertando para a diversidade da floresta estudada, resultados esses que foram comparados com outros estudos realizados na floresta Amazônica e mostrou que o nível de preservação da área de pesquisa, é adequada para os padrões de florestas de terra firme na Amazônia brasileira.

\section{AGRADECIMENTOS}

À Coordenação de Aperfeiçoamento de Pessoal em Nível Superior - CAPES, pela concessão da bolsa durante os quatro anos do curso de doutorado. Á Fundação de Amparo a Pesquisa do Amapá- FAPEAP pelo financiamento do projeto de pesquisa que deu origem a tese de doutorado. Á Empresa Brasileira de Pesquisa Agropecuária- Embrapa, pelo apoio logístico

\section{REFERÊNCIAS}

AB'SABER, A. N. Províncias geológicas e domínios morfoclimáticos no Brasil. Geomorfologia, São Paulo, 20. 26p,1970.

ALMEIDA, L. S.; GAMA, J. R. V.; OLIVEIRA, F. A.; CARVALHO, J.
O. P.; GONÇALVES, D. C. M.; ARAÚJO, G. C. Fitossociologia e uso múltiplo de espécies arbóreas em floresta manejada, Comunidade Santo Antônio, município de Santarém, Estado do Pará. Acta Amazônica, v. 42, n. 2, p. 185-194, 2012.

ANDRADE, D. F.; GAMA, J. R. V.; MELO, L. O.; RUSCHEL, A. R. Inventário florestal de grandes áreas na Floresta Nacional do Tapajós, Pará, Amazônia, Brasil. Biota Amazônia, Macapá-AP, v. 5, n. 1, p. 109-115, 2015.

ANDRADE, R. T. G.; PANSINI, S.; SAMPAIO, A. F.; RIBEIRO, M. S.; CABRAL, G. S.; MANZATTO, A. G.; Fitossociologia de uma floresta de terra firma na Amazônia Sul-Ocidental, Rondônia, Brasil. Biota Amazônia, Macapá-AP, v. 7, n. 2, p. 36-43, 2017.

BARBOSA, L. R. Conservação da biodiversidade e gestão participativa na Amazônia: o caso da Reserva Sustentável do Rio Iratapuru (Amapá, Brasil). Relatório de pesquisa. Holos Meio Ambiente e Desenvolvimento. Paris, FR. 106p, 2001.

BATISTA, A. P. B.; APARÍCIO, W. C. S.; APARÍCIO, P. S.; SANTOS, V. S.; LIMA, R. B.; MELLO, J. M. Caracterização estrutural em uma floresta de terra firme no estado do Amapá, Brasil. PFB, Colombo, v.35, n. 81, p. 21-33, jan./mar., 2015. BATISTA, A. P. B.; SANTOS, V. S.; APARÍCIO, W. C. S.; APARÍCIO, P. S.; SILVA, D. A. S. Similaridade e gradientes de riqueza florística em uma floresta de várzea na cidade de Macapá. Revista Verde de Agroecologia e Desenvolvimento Sustentável, Mossoró-RN, v. 8, n. 4, p. 152-158, out./dez., 2013.

CARIM, M. J. V.; GUILLAUMET, J. L. B.; GUIMARÃES, J. R. S.; TOSTES, L. C. L. Composição e estrutura de floresta ombrófila densa do extremo norte do Estado do Amapá, Brasil. Biota Amazônia, Macapá-AP, v. 3, n. 2, p. 1-10, 2013.

CHAVES, A. D. C. G.; SANTOS, R. M.de S.; SANTOS, J. O.; FERNANDES, A. A.; MARACAJÁ, P. B. A importância dos levantamentos florístico e fitossociológico para a conservação e preservação das florestas. ACSA Agropecuária Científica no Semiárido, v.9, n.2, p. 43-48, abr./jun., 2013.

CONDÉ, T. M.; TONINI, H. Fitossociologia de uma floresta ombrófila densa na Amazônia setentrional, Roraima, Brasil. Acta Amazônica, v. 43, n. 3, p. 247-260, 2013.

DIONISIO, L. F. S.; BONFIM FILHO, O. S.; CRIVELLI, B. R. S.; GOMES, J. P.; OLIVEIRA, M. H. S.; CARVALHO, J. O. P. Importância fitossociológica de uma fragmento de floresta ombrófila densa no Estado de Roraima, Brasil. Revista Agro@mbiente On-line, v. 10, n. 3, p. 243-252, jul./set. 2016.

FERREIRA JUNIOR, E. V.; SOARES, T. S.; COSTA, M. F. F.; SILVA; V. S. M. Composição, diversidade e similaridade florística de uma floresta tropical semidecídua submontana em 
Marcelândia-MT. Acta Amazônica, v. 38, n. 4, p. 673-680, 2008.

FREITAS, W. K.; MAGALHÃES, L. M. S. Métodos e parâmetros para estudo da vegetação com ênfase no estrato arbóreo. Floresta e Ambiente, v. 19, n. 4, p. 520-540, out./dez., 2012.

GOVERNO DO ESTADO DO AMAPÁ (GEA). Análise de viabilidade econômica da industrialização dos produtos derivados da castanha-do-brasil na Reserva de Desenvolvimento Sustentável do Rio Iratapuru. Relatório técnico. Macapá, AP. 37p. 1999.

GUIMARÃES, J. R. S.; CARIM, M. J. V. Análise fitossociológica e florística em três hectares de floresta tropical ombrófila densa na Reserva de Desenvolvimento Sustentável do Rio Iratapuru. Revista Pesquisa e Iniciação Científica, Amapá, v. 1, p. 32-34, 2008.

INSTITUTO DE PESQUISAS CIENTÍFICAS E TECNOLOGICAS DO ESTADO DO AMAPÁ (IEPA). Macrodiagnóstico do estado do Amapá, primeira aproximação do ZEE. 3. ed. Revisada e Ampliada, Macapá-AP, 139 p. 2008.

LIMA, R. B. A.; SILVA, J. A. A.; MARANGON, L. C.; FERREIRA, R. L. C.; SILVA, R. K. S. Fitossociologia de um trecho de floresta ombrófila densa na Reserva de Desenvolvimento Sustentável Uacari, Carauari, Amazonas. SCIENTIA PLENA, v. 8, n. 1, 12p, 2012.

LUANA, F. B. P. Análise da fitossociologia de uma área de terra firme no Rio Maués Mirim, município de Maués-AM. Dissertação, Itacoatiara-AM, 2017.

MELO, A. S. What do we win 'confounding' species richness and evenness in a diversity index? Biota Neotropica, v. 8, n. 3, p. 21-27, jul./set., 2008.

MENEZES, C. M.; FIGUEIREDO, F. L. S.; SANTANA, F. D.; AGUIAR, L. G. P. de. Caracterização florísticafitossociológica de fragmentos de floresta ombrófila densa da microbacia do Rio dos Cágados, Ituberá, Bahia. Revista AGIR de Ambiente e Sustentabilidades, Ibirapitanga-BA, v. 2, n. 1, p. 12-26, 2010.

OLIVEIRA, E. K. B. Dinâmica de uma floresta tropical manejada na Amazônia Oriental. Dissertação, Brasília-DF, 2016a.

OLIVEIRA, E. K. B.; NAGY A. C. G.; BARROS, Q. S.; MARTINS, B. C.; MURTA JUNIOR, L. S. Composição florística e fitossociológica de fragmento florestal no sudoeste da Amazônia. Enciclopédia Biosfera, Goiânia-GO, v. 11, n. 21, p. 2126-2146, 2015.

OLIVEIRA, O. A. Florística e Fitossociologia de fragmentos em área ecotonal Cerrado-Pantanal no município de Santo Antônio do Leverger-Mato Grosso. Dissertação, CuiabáMT, 2011.

OLIVEIRA, W. L. Estrutura, regras de montagem e dinâmica de florestas de terra firme, várzea e campinaranas: respostas ao gradiente ambiental e reservatório de uma hidrelétrica na Amazônia, bacia do alto Rio Madeira-RO. Tese de doutorado, Brasília-DF, 2016.

PEREIRA, L. A.; PINTO SOBRINHO; F. de A.; COSTA NETO, S. V da. Florística e estrutura de uma mata de terra firme na Reserva de Desenvolvimento Sustentável Rio Iratapuru, Amapá, Amazônia Oriental, Brasil. FLORESTA, Curitiba, PR, v. 41, n. 1, p. 113-122, jan./mar. 2011.

PERONI, N.; HERNÁNDEZ, M. I. M. Ecologia de populações e comunidades. Florianópolis-SC, 2011.

PINHEIRO, K. A. O.; CARVALHO, J. O. P.; QUANZ, B.; FRANCEZ, L. M. B.; SCHWARTZ, G. Fitossociologia de uma área de preservação permanente no leste da Amazônia: indicação de espécies para recuperação de áreas alteradas. Floresta, Curitiba, PR, v. 37, n. 2, p. 175-187, mai./ago. 2007.

PLANO DE MANEJO RESERVA DE DESENVOLVIMENTO SUSTENTÁVEL RIO IRATAPURÚ, GOVERNO DO ESTADO DO AMAPÁ, 2015.

SANTOS, K. P. C. Detecção da estrutura florestal aplicando o método foto em ecossistema de terra firme na Amazônia Oriental: primeiros resultados. Dissertação, Macapá-AP, 2017.

SANTOS, R. O. dos; ABREU, J. C.; LIMA, R. B.; APARÍCIO, P. da S.; SOTTA, E. D.; LIMA, R. C. Distribuição diamétrica de uma comunidade arbórea na Floresta Estadual do Amapá, Brasil. Biota Amazônia, Macapá-AP, v. 6, n. 2, p. 24-31, 2016.

SCHILLING, A. C.; BATISTA, J. L. F. Curva de acumulação de espécies e suficiência amostral em florestas tropicais. Revista Brasil, v. 31, n. 1, p. 179-187, jan./mar., 2008.

SCHILLING, A. C.; BATISTA, J. L. F.; COUTO, H. Z. Ausência de estabilização da curva de acumulação de espécies em florestas tropicais. Ciência Florestal, Santa Maria-RS, v. 22, n. 1, p. 101-111, jan./mar., 2012.

SILVA, K. E. Florística e estrutura espacial: 15 hectares de parcelas permanentes na Floresta densa de terra firme na Amazônia central. Tese, Viçosa-MG, 2010.

SILVA, K. E.; MATOS, F. D. A.; FERREIRA, M. M. Composição florística e fitossociologia de espécies arbóreas do Parque Fenológico da Embrapa Amazônia Ocidental. Acta Amazônia, v. 38, n. 2, p. 213-222, 2008.

SILVA, W. A. S.; CARIM, M. J. V.; GUIMARÃES, J. R. S.; TOSTES, L. C. L. Composição e diversidade florística em um trecho de Floresta de terra firme no sudoeste do Estado do Amapá, Amazônia Oriental, Brasil. Biota Amazônia, Macapá-AP, v.4, n.3, p. 31-36, 2014.

SILVA, W. C.; MARAGON, L. C.; FERREIRA, R. L. C.; FELICIANO, A. L. P.; APARÍCIO, P. S.; COSTA JUNIOR, R. F. Estrutura horizontal e vertical do componente arbóreo em fase de regeneração natural na mata Santa Luzia, no município de Catende-PE. Revista Árvore, Viçosa-MG, v. 34, n. 5, p. 863869, 2010. 
SOARES, C. P. B.; NETO, F. P.; SOUZA, A. L. Dendrometria e Inventário Florestal. Editora UFV, Viçosa-MG, 272p, 2011.

SOUSA, C. S. C.; SILVA, D. A. S.; APARÍCIO, P. S.; SILVA, W. C.; SILVA, E. F.; ALMEIDA, M. R. D. Diversidade e similaridade florística em áreas sob influência de uma usina hidrelétrica na Amazônia. Revista em Agronegócio e Meio Ambiente, Maringá-PR, v. 11, n. 4, p. 1195-1216, 2018.

SOUZA, A. L.; SOARES, C. P. B. Florestas Nativas: estrutura, dinâmica e manejo. Editora UFV, Viçosa-MG, 322p, 2013.

Submissão: 16/10/2019

Aprovado para publicação: 01/11/2019 